\title{
Advancing Community Pharmacy Practice - A Technician Product Verification Pilot to Optimize Care
}

Michael Andreski, RPh, MBA, PhD¹; Erica Martin, BS²; Victoria Valentine Brouner, RN, MS, PharmD, PhD ${ }^{3}$; Sarah Sorum, PharmD ${ }^{2}$

${ }^{1}$ Drake University College of Pharmacy and Health Sciences; ${ }^{2}$ Pharmacy Society of Wisconsin;

${ }^{3}$ Concordia University Wisconsin School of Pharmacy

\begin{abstract}
Elevating the technical role of pharmacy technicians to perform Technician Product Verification (TPV) is one strategy that has shown promise to optimize pharmacy practice models. This is done by better positioning pharmacists to provide clinical care, in line with their education and expertise. TPV permits a Validated Pharmacy Technician, as defined by the Wisconsin Pharmacy Examining Board, to verify the accuracy of a product filled by another technician. The pharmacist maintains responsibility for assessing the clinical appropriateness of the prescription, including drug utilization review, data entry, and patient counseling.
\end{abstract}

During the study period, 12,891 pharmacist-verified prescriptions (baseline) and 27,447 Validated Pharmacy Technician-verified prescriptions were audited for accuracy. The aggregate verification error rate for pharmacist-verified prescriptions was $0.16 \%$ and $0.01 \%$ for Validated Pharmacy Technician-verified prescriptions. The mean error rate was significantly less for Validated Pharmacy Technician-verified prescriptions than for pharmacist-verified prescriptions $(0.19 \pm 0.174 \%$ vs $0.03 \pm 0.089 \%, p=0.020)$ (Figure 3 ).

This suggests TPV in the community pharmacy setting maintained patient safety. In this study, Validated Pharmacy Technicians were shown to be more accurate than pharmacists at performing product verification. The ability to delegate the product verification task holds the potential to free up pharmacist time for increased direct patient care. Increasing direct patient care by pharmacists in community pharmacies may have significant implications for improving patient outcomes and pharmacy quality.

Keywords: Technician Product Verification; Product Verification; Delegate-Check-Delegate; Tech-Check-Tech; Optimizing Care; Pharmacy Care; Community Pharmacy; Pharmacy Technician

\section{Introduction}

The need for widespread delivery of patient care services at community pharmacies is growing. In the context of a predicted physician shortage ${ }^{1}$ and an aging population with increased prevalence of chronic conditions and medication use, ${ }^{2}$ community pharmacists are poised and qualified to support enhanced clinical care for patients. Pharmacists are in a position to support and expand patient care services, evolving the community pharmacy practice model to improve patient-care, as $91 \%$ of Americans live within five miles of a community pharmacy. ${ }^{3}$ In order for community pharmacies to feasibly offer clinical care more broadly and meet the needs of patients, current practice models must be adapted to optimize patient care.

Elevating the technical role of pharmacy technicians to perform Technician Product Verification (TPV) is one strategy that has shown promise to optimize pharmacy practice models by better positioning pharmacists to provide clinical care, in line with their education and expertise. TPV permits a trained and validated pharmacy technician, known as a Validated Pharmacy

Corresponding author: Erica Martin, BS

Pharmacy Society of Wisconsin

Email: emartin@pswi.org
Technician, to verify the accuracy of a product filled by another technician, while the pharmacist maintains responsibility for assessing the clinical appropriateness of all prescriptions. "Final product verification" historically has been completed by a pharmacist, as required by state law, however, the time a pharmacist spends completing product verification can be substantial. ${ }^{4}$ By permitting trained and qualified pharmacy technicians to complete this technical task, pharmacists can redirect more time and attention toward direct patient care.

\section{Past Research}

Research suggests that pharmacists spend a substantial amount of time performing product verification and trained pharmacy technicians can perform the same task with similar accuracy rates to pharmacists. A study conducted by Reed et al. (2011) in an academic medical center hospital observed the time pharmacists spent on product verification decreased by $94.5 \%$ when technician product verification was initiated. ${ }^{5}$ Tarver et al. (2017) studied the impacts of technician product verification on automated medication supply systems in an academic medical center. The study demonstrated a significant decrease in the time pharmacists spent on product verifications for the total automated medication supply system, STAT medication orders, and routine orders. ${ }^{6}$ In a 1991 study conducted by Woller et al., pharmacy technicians who completed didactic and practical training completed the product verification of unit dose carts with artificial errors and were at least $99.94 \%$ 
accurate. ${ }^{7}$ Additional studies that followed $8,9,10,11$ showed pharmacy technicians and pharmacists perform product verifications with similar accuracy.

While compelling, the majority of previous research has focused on technician product verification in the inpatient or institutional setting. lowa's New Practice Model pilot program was the first statewide pilot of community setting-based technician product verification in the country. This concept study by Andreski et al. confirmed that TPV can be implemented safely in the community pharmacy setting, replicating findings from inpatient practice. The study piloted TPV, with an emphasis on redirecting pharmacist time to patient care, in seven pharmacies over 18 months. During this time, there was no significant difference in product verification overall errors $(0.2729 \%$ vs. $0.5124 \%, P=0.513)$, patient safety errors $(0.0525 \%$ vs. $0.0651 \%, P=0.837)$ or administrative errors $(0.2204 \%$ vs. $0.4784 \%, P=0.411)$ when product verification was completed by pharmacists versus pharmacy technicians. The New Practice Model study also evaluated how pharmacists spent their time prior to and post-implementation of technician product verification. Pharmacist time spent on dispensing, including completing the product verification, decreased significantly $(67.3 \%$ vs. $49.06 \%)$ while direct patient care increased significantly (19.96\% vs. $34.72 \%, P=0.003) .{ }^{12}$

Further, the University of Wisconsin Health completed a feasibility study in a mail order and health-system outpatient pharmacy. The four-week study analyzed the accuracy of a pharmacy technician at completing the product verification as audited by a pharmacist. It was determined technicians were as accurate as pharmacists at completing product verification (99.95\% vs. 99.74\%), and the new workflow permitted the pharmacist in the outpatient pharmacy to have a projected additional 23 days per year worth of pharmacist time to spend on direct patient care. ${ }^{13}$

Given the successes of the lowa pilot study and a Wisconsin health system feasibility study, a second pilot study was initiated in Wisconsin to assess the effects of technician product verification on patient safety and pharmacy practice in the community setting. This community setting pilot sought to demonstrate the replicability of lowa's initial pilot findings in another context to potentially support broader replicability of the model across the country.

\section{Wisconsin Pilot Authority}

Wisconsin statute $450.02(3 r)$ allows the Wisconsin Pharmacy Examining Board to authorize pilot programs related to pharmacy or prescription verification, or pilots that will improve the safety, quality, or efficiency of the practice of pharmacy in Wisconsin for up to three years. ${ }^{14}$ Such permissions include waiving statutes, such as the requirement for pharmacists to complete product verification.

\section{Objective}

Assess the impact of technician product verification in community pharmacies in Wisconsin on patient safety measures and on facilitating community pharmacist-provided services.

\section{Methods \\ Study Design}

The study design was a single group, pre-test - post-test comparison using t testing. Data was self-reported in aggregate for the pharmacy, not by individual pharmacists or Validated Pharmacy Technicians. Therefore, the unit of analysis was the pharmacy, not individual pharmacists or Validated Pharmacy Technicians.

In all phases of data collection, individual data was aggregated and de-identified by each pharmacy before being submitted to Concordia University Wisconsin School of Pharmacy via Qualtrics Survey Hosting Service.

The Wisconsin TPV pilot was approved by the Pharmacy Examining Board from November 1, 2016-October 1, 2019, and the study period and data collection ran from January 1, 2017, to December 31, 2017.

\section{Pharmacy Requirements}

In order to participate in the Wisconsin TPV pilot, the pharmacy had to comply with Wisconsin Pharmacy Examining Board requirements, including: ${ }^{15}$

- A pharmacist assessed the clinical appropriateness and provided consultation to a patient on each prescription dispensed at the pharmacy. This statutory and regulatory requirement in Wisconsin preceded the study and exists independently from the TPV pilot.

- The pharmacy implemented TPV quality assurance measures that were added to the pharmacy's preexisting quality assurance plan, in accordance with the pilot requirements.

- Validated Pharmacy Technicians were permitted to complete the product verification of any noncompounded, non-reconstituted, non-mailed, and nondelivered prescription. However, if a prescription encountered a technology override (e.g., National Drug Code change), the product verification could not be completed by a Validated Pharmacy Technician.

- Implementation of TPV was not intended to reduce pharmacist staffing levels but was intended to increase the availability of a pharmacist for involvement in other patient care activities. In the pharmacy application, the pharmacy attested to the Wisconsin Pharmacy Examining Board that the pilot was to "be utilized to provide direct patient care services and is not intended to reduce staffing levels." 16 
- Prior to completing product verification independently, Validated Pharmacy Technicians completed didactic training and practical training in accordance with curriculum components required by the Wisconsin Pharmacy Examining Board and developed by the Pharmacy Society of Wisconsin. All Validated Pharmacy Technicians were required to achieve at least an accuracy rate of $99.8 \%$ after completing the product verification of 1,000 prescriptions that were audited by a pharmacist. ${ }^{17}$ Prior studies evaluating TPV have also implemented requirements for training and/or validation. ${ }^{18,19,20}$

\section{Pharmacy Recruitment}

Participating pharmacies were identified and selected based on their prior exemplary record of performing enhanced pharmacist-provided patient care services, signifying their ability to expand these services upon technician product verification implementation. Many of the inquiries for participation in the pilot were identified through the Pharmacy Society of Wisconsin's Wisconsin Pharmacy Quality Collaborative, a network of accredited, high-quality pharmacies with trained and certified pharmacists who provide medication therapy management services to patients with chronic conditions, complex medication regimens, or low health literacy. ${ }^{21}$

The study team contacted four chain pharmacy organizations, six health-systems, and eleven independent organizations to inquire about their interest in having up to three of their pharmacies participate in the pilot. In total, 16 pharmacies from three chain pharmacy organizations, four health-system organizations, and three independent pharmacies organizations elected to participate in the pilot.

\section{Procedures}

Assess Effect of TPV on Patient Safety

The impact of technician product verification on patient safety was assessed by comparing the accuracy of Validated Pharmacy Technicians' completing the product verification of a prescription to the accuracy of a pharmacist completing the product verification of a prescription.

To establish baseline, the accuracy of participating pharmacists at completing the product verification was determined. A prescription was filled by a pharmacy technician, product verified by a pharmacist, and product verified for a second time by a different pharmacist, pharmacist intern, or Validated Pharmacy Technician. Data was collected on baseline product verification errors including incorrect drug, dose, dosage form, or quantity, or other errors as determined by the pharmacy. Data was collected for a minimum of 50 prescriptions per day for 15 days for a minimum total of 750 prescriptions per pharmacy (Figure 1).

Once TPV was implemented, to assess the accuracy rate of the Validated Pharmacy Technician, a prescription was filled by a pharmacy technician, then the product was verified by a Validated Pharmacy Technician, and the product was then verified again by a pharmacist (Figure 2). Validated Pharmacy Technicians and pharmacist interns were not able to serve as the second product verification during daily quality assurance audits of another Validated Pharmacy Technician in accordance with the approved pilot procedures. ${ }^{22}$

A pharmacist audited a minimum of five percent of the total number of prescriptions that were product verified by each Validated Pharmacy Technician each day. The quantity of data collected - five percent daily - was chosen to align with quality assurance measures required by the Wisconsin Pharmacy Examining Board. ${ }^{23}$ For example, a technician completed the product verification of 100 prescriptions during the day. The pharmacist audited 5 of those prescriptions to determine if the Validated Pharmacy Technician correctly completed the product verification. Data was collected on product verification errors involving incorrect drug, dose, dosage form, or quantity, or other errors as determined by the pharmacy.

On a monthly basis, aggregate data for each pharmacy was collected. This included the total number of prescriptions that were filled at the pharmacy, the total number of prescriptions that were product verified by a Validated Pharmacy Technician, the total number of product verifications completed by Validated Pharmacy Technicians which were audited by a pharmacist, the total number of errors identified by a pharmacist during the audits, and the specific errors identified. Once submitted to the research team, the rate of verification errors was calculated for each pharmacy individually and for all of the pharmacies combined. 
Figure 1. Process to Establish the Accuracy of Pharmacists at Completing the Product Verification (Baseline)

\section{Prescription Filled}

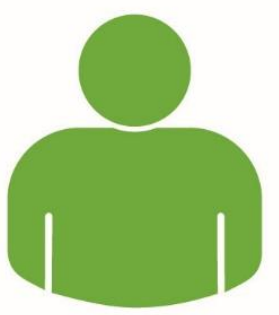

Technician
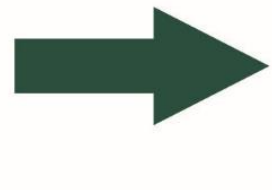
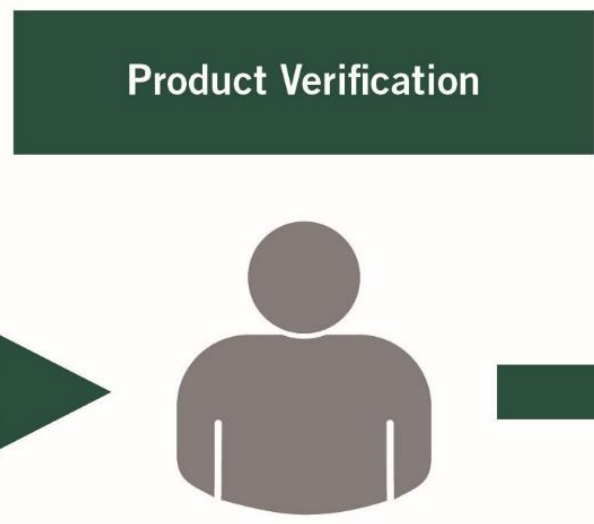

Pharmacist

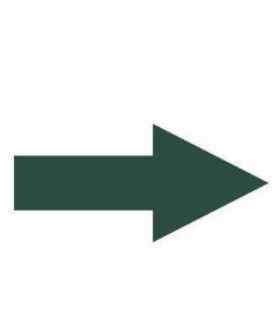

(1)

\section{Audit of Product Verification}

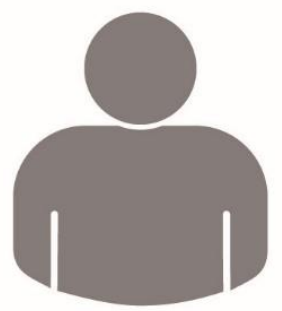

Pharmacist,

Pharmacist Intern, or Validated Pharmacy Technician

Figure 2. Process to Establish the Accuracy of Validated Pharmacy Technicians at Completing the Product Verification

\section{Prescription Filled}

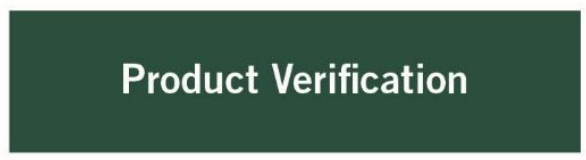

\section{Audit of Product Verification}

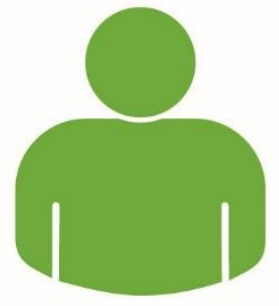

Technician

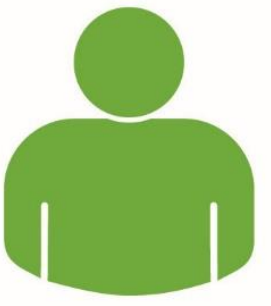

Validated Pharmacy Technician
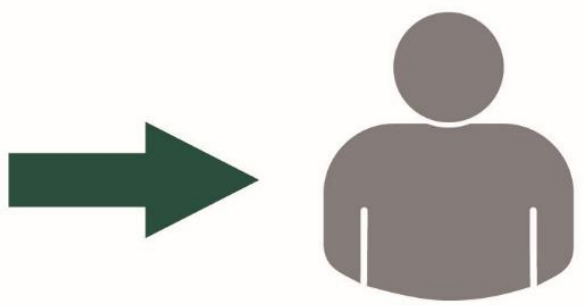

Pharmacist 
Assess Effect of TPV on Pharmacist Workday Composition and Provision of Patient Care

The impact of technician product verification in community pharmacies in Wisconsin in facilitating community pharmacistprovided services was assessed by measuring how pharmacists' time was allocated prior to and post-technician product verification implementation.

Pharmacists self-reported the activities they completed during the workday at both baseline and after technician product verification implementation. Baseline data was collected for a minimum of 15 consecutive days to account for fluctuations based on day of the week, vacation, and other absences. Posttechnician product verification implementation, pharmacists continued to self-report the activities they completed during each day for which technician product verification was used. Time allocation data was not collected for pharmacist interns, as they do not complete managerial activities, which must be accounted for to provide an accurate depiction of the effect of technician product verification on pharmacist time.

\section{Results}

Of the 16 pharmacies that participated, one pharmacy withdrew from the pilot due to staffing turnover and two pharmacies (within the same organization) withdrew due to a new computer software system that did not permit a fluid workflow for technician product verification. The study concluded with 13 pharmacies submitting data: six chain pharmacies, five outpatient health-system pharmacies, and five independent pharmacies.

\section{Effect of TPV on Patient Safety}

During the study period, 12,891 pharmacist-verified prescriptions (baseline) and 27,447 Validated Pharmacy Technician-verified prescriptions were audited for accuracy. The aggregate verification error rate for pharmacist-verified prescriptions was $0.16 \%$ and $0.01 \%$ for technician verified prescriptions. The mean rate was significantly less for Validated
Pharmacy Technician-verified prescriptions than for pharmacist-verified prescriptions $(0.19 \pm 0.174 \%$ vs $0.03 \pm$ $0.089 \%, p=0.020$ ) (Figure 3).

Effect of TPV on Pharmacist Workday Composition and Provision of Patient Care

Only one pharmacy consistently completed data collection for ten months of the intervention period. The range of months collected by the other pharmacies ranged from one month for three of the pharmacies to seven months for the remaining pharmacy. The mean number of months collected was 3.77 and the median was 4 . The number of pharmacies reporting in a month ranged from one pharmacy in two months to ten pharmacies in one month. The mean number of pharmacies reporting per month was 4.9 and the median was 4.5. In addition to an inconsistent number of pharmacies reporting pharmacists' workday composition each month, examination of the amount of time submitted for many of the months indicated that not all pharmacist activity was being recorded, as there was a significant difference between the number of hours reported and the expected number of hours based on staffing levels. Due to incomplete and inconsistent data reporting, no aggregate analysis of pharmacist workday composition was performed.

As stated above, one pharmacy did consistently report pharmacist workday composition at baseline for ten months during the active intervention period. Comparing the pharmacist activity times with staffing at this site also indicated that most of the pharmacists' activities were being reported. For this pharmacy, during baseline determination, $25.9 \%$ of pharmacists' time was spent in patient care activities, $12.35 \%$ of the time in management activities, and $61.73 \%$ in dispensing activities. Over the ten months of technician product verification, the amount of time spent in patient care activities was $58.62 \%$, while $22.96 \%$ of time was spent in management activities, $4.73 \%$ in other activities, and $13.70 \%$ in dispensing activities. 
Figure 3. Accuracy of Completing the Product Verification Results

Prescription Filled

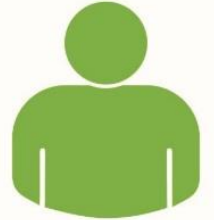

Technician
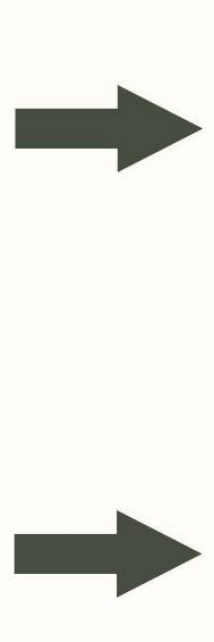

Technician

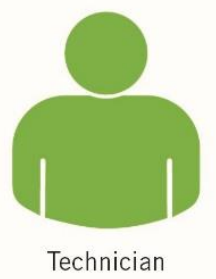

(1)
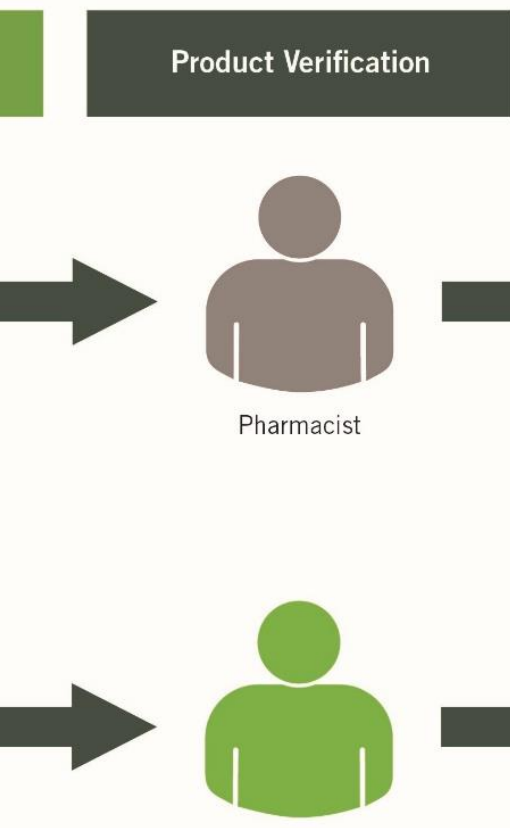

Validated Pharmacy
Pharmacist

Technician
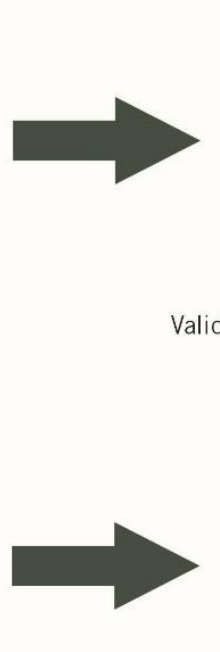

Technician
Audit of Product Verification

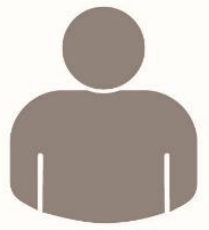

Pharmacist,

Pharmacist Intern, or

Validated Pharmacy Technician

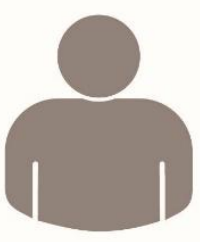

Pharmacist
Accuracy Rate of

Product Verification as Confirmed by Audit

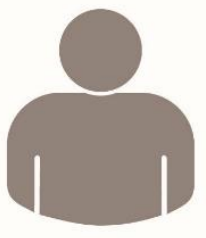

$99.81 \%$

Pharmacist

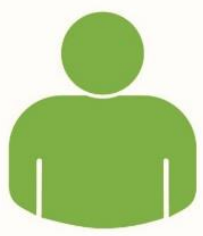

$99.97 \%$

Validated Pharmacy Technician

\section{Discussion}

\section{Impact of TPV on Patient Safety}

Pharmacists demonstrated a very low baseline rate of errors during product verification. The rates were similar to a recent study in lowa that had examined the verification error rate in community pharmacies $(0.19 \pm 0.174 \%$ vs $0.48 \pm 0.23 \%) .{ }^{24}$ In the Wisconsin study, once technician product verification was implemented, there was a significant decrease in the rate of verification errors $(0.19 \pm 0.174 \%$ vs $0.03 \pm 0.089 \%, p=0.020)$. The rate of verification errors in technician verified prescriptions in the current study was lower than in the lowa study mentioned earlier $0.03 \pm 0.089 \%$. These findings suggest TPV can be safely performed by pharmacy technicians with specific training on TPV as part of an optimizing care model.

\section{Impact of TPV on Pharmacist Workday Composition and} Provision of Patient Care

For the pharmacy that reported consistently during both the baseline and intervention periods of the study, when TPV was initiated in the pharmacy, the amount of time pharmacists reported providing patient care services more than doubled from $25.9 \%$ to $58.62 \%$ while dispensing activities decreased from $61.73 \%$ to $13.7 \%$ of the pharmacists' time. This is similar to what was seen in the recent lowa study that had examined the effect of the initiation of technician product verification on pharmacists' workday composition and provision of patient care. In the lowa study, the time pharmacists spent dispensing decreased by $29.7 \%$ while time spent providing patient care increased by $26.4 \%$.

The results of our Wisconsin pilot, in the context of research to date, indicate that using technician product verification can greatly decrease the amount of time pharmacists spend on dispensing activities that do not require clinical judgement, with that time being redirected to increase pharmacists' capacity to provide patient care activities and deploy their clinical expertise to improve care.

\section{Challenges / Lessons Learned}

Pharmacy Technician Validation Process

One challenge to efficient technician product verification implementation in this pilot was the amount of time required to complete the product verification of 1,000 prescriptions that were then audited by a pharmacist for accuracy. The pharmacy 
technician was required to be $99.8 \%$ accurate to become a Validated Pharmacy Technician. A pharmacy technician could not complete the product verification of a prescription they filled. ${ }^{25}$

Therefore, staffing must be adequate to allow another pharmacy technician to be filling simultaneously, or pre-filling prescriptions, for the pharmacy technician being validated. Pharmacies found it challenging to remove a staff member being validated from their workflow to complete this validation process. Because a pharmacist was required to complete the second verification, this eliminated the possibility of utilizing a pharmacist intern as another staff member to complete the process. In pharmacies that were attempting to validate more than one pharmacy technician, this was an even larger challenge. Further, in pharmacies with small prescription volumes, this process took weeks to months to validate one pharmacy technician. In other studies, the requirements for the verification technicians were based on overall and site-specific experience as a pharmacy technician.

Based on this experience, the research team would suggest that future evaluations of technician product verification consider other performance-based methods and site-specific factors for technician validation and seek to facilitate an efficient validation process for technicians while maintaining safeguards for patient safety. This helps ensure that the impact of technician product verification, which is designed to improve efficiencies and advance pharmacist-provided care for patients, is not undermined due to cumbersome, lengthy validation requirements and processes.

\section{Computer Software Capabilities and Refinements}

Participating pharmacies experienced difficulties delegating product verification privileges to Validated Pharmacy Technicians due to lacking capabilities in their computer systems. Validated Pharmacy Technicians having such abilities in their computer programs was not a requirement of the pilot or the study, but the Pharmacy Society of Wisconsin found it essential to gaining trust and support from organizational leadership, pharmacists, and pharmacy technicians.

Changes in the computer system required engagement from technology departments and organizational leadership to create a new Validated Pharmacy Technician category within the software program. Because each pharmacy organization may use a different computer system, peer-to-peer sharing could not be leveraged. However, once a Validated Pharmacy Technician category was created in the computer system, the pharmacists were able to pull technician product verification reports quickly instead of manually collecting data.

The research team suggests that future evaluations of technician product verification prioritize the ability for technicians to perform TPV in workflow via new category designation in the pharmacy software system.

\section{Staffing Changes Impact on Pilot Requirements}

Many pharmacies in this study faced staffing turnover. In accordance with pilot requirements, Validated Pharmacy Technicians were required to have "a minimum of 2000 hours of experience as a pharmacy technician or completion of an accredited pharmacy technician training program." Further, they were required to have "at least 6 months of employment as a pharmacy technician at any pharmacy within the organization." 26 Staffing turnover occurred with Validated Pharmacy Technicians, occasionally causing the challenge of finding a qualifying replacement. The pilot requirement made it difficult, if not impossible, to replace any Validated Pharmacy Technician who left a pharmacy during the course of the study. Often a Validated Pharmacy Technician had to fill in for another staff member, and technician product verification was delayed until the staff was once again at full capacity.

A lesson learned was that once the pharmacy begins to utilize technician product verification, the Validated Pharmacy Technician staffing is critical. And from prior literature and experience, the impact of Technician Product Verification is maximized when the new workflow model is implemented consistently over time. ${ }^{27}$ Not having a Validated Pharmacy Technician requires the pharmacy to revert back to a traditional model of pharmacist verification of prescriptions with resulting implications for the pharmacists' ability to optimize patient care services. Therefore, to minimize disruptions, the study team recommends that pharmacies implementing TPV include training and validating of multiple qualifying technicians at a site, and rotating verification duties, so that multiple technicians are equipped to perform product verification if staffing challenges are encountered.

\section{Limitations}

Due to logistical issues arising from the implementation of technician product verification, data collection on the pharmacists' workday composition was limited. This precluded a robust statistical analysis of the effects of initiating technician product verification on redirection of pharmacist time. While the positive changes seen in one pharmacy were similar to those seen in another similar study in lowa, these changes may not be reflective of the experience in all of the pharmacies in the pilot. As self-reported data was used, the potential for social desirability bias exists.

Pharmacists expressed concern with documenting their time throughout the day as it is time-consuming, disruptive to their workflow, and detracts from patient care. For future evaluations of Technician Product Verification, the study team recommends implementing a standardized process to consistently track pharmacist time and address barriers to measure and report pharmacist time on an ongoing basis. The research may not be applicable to pharmacies subject to different regulatory requirements. 


\section{Conclusions}

This study suggests technician product verification in the community setting can maintain patient safety. The results of this study are similar to previous studies regarding the abilities of pharmacy technicians to verify the product in a filled prescription. In this study, Validated Pharmacy Technicians were shown to be more accurate than pharmacists in performing product verification. This suggests that technician product verification is safe for completing the common and time intensive task of product verification, which is currently performed by pharmacists as required by law in most states.

The ability to delegate the product verification task holds the potential to free up pharmacist time for increased direct patient care. Increasing direct patient care by pharmacists in community pharmacies may have significant implications for improving patient outcomes and pharmacy quality. Due to several issues mentioned earlier, a large-scale assessment of the effect of this transfer on pharmacists' ability to provide services was not possible in this pilot. One pharmacy was able to complete the duration of the study using technician product verification and the results in this pharmacy were similar to the results found in previous research at a similar time after implementation of technician product verification.

This study is also a reminder of the challenges that can arise when performing practice-based research, including challenges that lead to delays in implementation and inconsistent and incomplete data collection. This reinforces the importance of a coordinated effort to begin research when participating sites are ready, and for continued contact with the participating pharmacies to help ensure full engagement and recordkeeping. Future Practice
The results of this study can be used to support efforts to expand technician product verification in Wisconsin and across the country. Since the study period, Wisconsin has codified the pilot language into Wisconsin regulations to make TPV permanent in the state. ${ }^{28}$ This research adds to the rapidly expanding amount of information being generated by other states' TPV pilot programs, reinforcing the safety and effectiveness of the process to optimize pharmacist-provided patient care. This study has potentially significant implications for optimizing community pharmacy-based patient care by improving the utilization of resources. The results of this study closely replicate previous, similar findings that technician product verification allows a repositioning of pharmacists to provide more patient care without compromising patient safety.

Acknowledgements: National Association of Chain Drug Stores, lowa Pharmacy Association, University of Wisconsin Health, Megan Myers, PharmD, Scott Hordesky, MBA, Christian Albano, MBA, MPH, PhD, Nicia Lemoine, and pharmacies and organizations who voluntarily participated and collected data for this study.

Funding: This project was funded by the National Association of Chain Drug Stores and the Pharmacy Society of Wisconsin.

Conflicts of Interest: The authors have no conflicts of interest to disclose.

Treatment of Human Subjects: This project was reviewed and approved by Concordia University Wisconsin School of Pharmacy Institutional Review Board.

\section{References}

${ }^{1}$ Dall T, Chakrabarti R, lacobucci W, Hansari A, Terry West. The Complexities of Physician Supply and Demand: Projections from 2015 to 2030. February 2017.

${ }^{2}$ Charlesworth CJ, Smit E, Lee DSH, Alramadhan F, Odden MC. Polypharmacy Among Adults Aged 65 Years and Older in the United States: 1988-2010. The Journals of Gerontology Series A: Biological Sciences and Medical Sciences. 2015;70(8):989-995. doi:10.1093/gerona/glv013.

${ }^{3}$ Face-to-Face with Community Pharmacies. National Association of Chain Drug Stores. https://www.nacds.org/pdfs/about/rximpactleavebehind.pdf.

${ }^{4}$ Wang BN, Brummond P, Stevenson JG. Comparison of barcode scanning by pharmacy technicians and pharmacists' visual checks for final product verification. American Journal of Health-System Pharmacy. 2016 Jan 15;73(2):69-75. doi: 10.2146/ajhp150135.

${ }^{5}$ Reed M, Thomley S, Ludwig B, Rough S. Experience with a "tech-check-tech" program in an academic medical center. 2011 Oct 1;68(19):1820-3. doi: 10.2146/ajhp100578.

${ }^{6}$ Tarver SA, Palacios J, Hall R, Franco-Martinez AC. Implementing a Tech-Check-Tech Program at a University Health System. Hospital Pharmacy. 2017;52(4):280-285. doi:10.1310/hpj5204-280.

${ }^{7}$ Woller TW, Stuart J, Vrabel R, Senst B. Checking of unit dose cassettes by pharmacy technicians at three minnesota hospitals. American Journal of Health-System Pharmacy. 1991;48(9):1952-1956. doi:10.1093/ajhp/48.9.1952.

${ }^{8}$ Spooner SH, Emerson PK. Using hospital pharmacy technicians to check unit dose carts. American Journal of Health-System Pharmacy.1994 May;29(5):433-7.

${ }^{9}$ Ness JE, Sullivan SD, Stergachis A. Accuracy of technicians and pharmacists in identifying dispensing errors. American Journal of HealthSystem Pharmacy. 1994;51(3):354-357. doi:10.1093/ajhp/51.3.354. 
${ }^{10}$ Klammer GA, Ensom RJ. Pharmacy technician refill checking: safe and practical. The Canadian Journal of Hospital Pharmacy. 1994 Jun;47(3):117-9, 122-3.

${ }^{11}$ Ambrose PJ, Saya FG, Lovett LT, Tan S, Adams DW, Shane R. Evaluating the accuracy of technicians and pharmacists in checking unit dose medication cassettes. American Journal of Health-System Pharmacy. 2002;59(15):1463-1463. doi:10.1093/ajhp/59.15.1463.

${ }^{12}$ Andreski M, Myers M, Gainer K, Pudlo A. The lowa new practice model: Advancing technician roles to increase pharmacists time to provide patient care services. Journal of the American Pharmacists Association. 2018;58(3). doi:10.1016/j.japh.2018.02.005.

${ }_{13}$ Miller RF, Cesarz J, Rough S. Evaluation of community pharmacy tech-check-tech as a strategy for practice advancement. Journal of the American Pharmacists Association. 2018;58(6):652-658. doi:10.1016/j.japh.2018.06.018.

${ }^{14}$ Wis. Stat. 450.02(3r). https://docs.legis.wisconsin.gov/statutes/statutes/450.pdf

${ }^{15}$ Community Tech-Check-Tech Pilot Program Information (DPD3189). dsps.wi.gov.

https://dsps.wi.gov/Documents/BoardCouncils/PHM/PilotPrograms/DPD3189.pdf. Published November 2016.

${ }^{16}$ Community Pharmacy Tech-Check-Tech (cTCT) Pilot Program Application (DPD3190). dsps.wi.gov.

https://dsps.wi.gov/Documents/BoardCouncils/PHM/PilotPrograms/DPD3190.pdf. Published November 2016.

${ }^{17}$ Community Tech-Check-Tech Pilot Program Information (DPD3189). dsps.wi.gov.

https://dsps.wi.gov/Documents/BoardCouncils/PHM/PilotPrograms/DPD3189.pdf. Published November 2016.

${ }^{18}$ Reed M, Thomley S, Ludwig B, Rough S. Experience with a "tech-check-tech" program in an academic medical center. 2011 Oct

1;68(19):1820-3. doi: 10.2146/ajhp100578.

${ }^{19}$ Woller TW, Stuart J, Vrabel R, Senst B. Checking of unit dose cassettes by pharmacy technicians at three minnesota hospitals. American Journal of Health-System Pharmacy. 1991;48(9):1952-1956. doi:10.1093/ajhp/48.9.1952.

${ }^{20}$ Ambrose PJ, Saya FG, Lovett LT, Tan S, Adams DW, Shane R. Evaluating the accuracy of technicians and pharmacists in checking unit dose medication cassettes. American Journal of Health-System Pharmacy. 2002;59(15):1463-1463. doi:10.1093/ajhp/59.15.1463.

${ }^{21}$ Trapskin K, Johnson C, Cory P, Boyce S, Decker C. Forging a novel provider and payer partnership in Wisconsin to compensate pharmacists for quality-driven pharmacy and medication therapy management services. Journal of the American Pharmacists Association. 2009;49(5):642-651. doi:10.1331/japha.2009.08158.

${ }^{22}$ Community Tech-Check-Tech Pilot Program Information (DPD3189). dsps.wi.gov. https://dsps.wi.gov/Documents/BoardCouncils/PHM/PilotPrograms/DPD3189.pdf. Published November 2016.

${ }^{23}$ Community Tech-Check-Tech Pilot Program Information (DPD3189). dsps.wi.gov. https://dsps.wi.gov/Documents/BoardCouncils/PHM/PilotPrograms/DPD3189.pdf. Published November 2016.

${ }^{24}$ Andreski, et al, The lowa New Practice Model: Full Implementation of an Initiative to Enable Pharmacists to Provide More Patient Care Services, Poster presented at 2019 American Pharmacy Association Meeting, Seattle, WA

${ }^{25}$ Community Tech-Check-Tech Pilot Program Information (DPD3189). dsps.wi.gov.

https://dsps.wi.gov/Documents/BoardCouncils/PHM/PilotPrograms/DPD3189.pdf. Published November 2016.

${ }^{26}$ Community Tech-Check-Tech Pilot Program Information (DPD3189). dsps.wi.gov.

https://dsps.wi.gov/Documents/BoardCouncils/PHM/PilotPrograms/DPD3189.pdf. Published November 2016.

${ }^{27}$ Andreski M, Myers M, Gainer K, Pudlo A. The lowa new practice model: Advancing technician roles to increase pharmacists time to provide patient care services. Journal of the American Pharmacists Association. 2018;58(3). doi:10.1016/j.japh.2018.02.005.

${ }^{28}$ Wisconsin Administrative Code Phar 7.21. 